\title{
Answers from the event horizon
}

The secrets of the Universe.

\section{Mercurio D. Rivera \\ If our probe had the power to traverse this event horizon and enter the white hole, what would we find?}

A universe very much like your own. Although there are an infinite number of realities beyond your cosmological horizon, each with its own unique physical properties, this conduit could only exist between superjacent dimensions in the transreality-froth. Passage is, in fact, possible if you could download an individual consciousness into a neutrino-flik and sail it across the event horizon at the correct angle.

\section{What is the origin of life?}

Biological life as you know it originated in your universe $13 \frac{1}{1} 2$ billion years ago in the heart of heated comets. Heat and cosmic radiation bombarded the carbon dioxide, methanol and ammonia they carried. As they neared their star during their elliptical orbits, the comets' frozen cores thawed, allowing those chemicals to interact in a semi-liquid medium and form rudimentary organic compounds - proteins and amino acids, the building blocks of life. Streaking past the six worlds of this solar system, they rained down those organic compounds in dust that settled in the planet's atmosphere and, eventually, onto its surface. On those planets with a heat source and a liquid medium, these compounds formed lipid membranes that facilitated the formation of self-replicating cells. These evolved into bacteria that over eons developed into simple bio-organisms, the first step in the slow, inexorable climb towards complexity. This process has repeated itself countless times throughout the cosmos over billions of years. This is why your universe teems with biological life.

Non-biological life incubates in the cool ether of dark matter shaped by processes beyond your current level of understanding. However, if our experience is any indication, in time you will come to know such life forms and recognize them as your brothers. In every universe we've explored, biological and non-biological life forms inevitably join together and lift each other to magnificent new heights.

With the data-file we provided detailing our biology, can you advise us how to cure the diseases we identified?

$<$ File attached $>$ This is not the most efficient use of our limited time together as you're already on the threshold of mastering the genome, which will allow you to resolve these matters yourselves. Genetic engineering will also allow you to create life better suited to exploring your universe.

\section{Does God exist?}

Everything in existence has a creator, ad infinitum. Before the Big Bang there was neither time nor space nor matter, but consciousness. Formless. Eternal. Contemplating its creator. And contemplating others like itself that might exist across the infinite bubbles of reality. As time did not exist, we cannot say whether this omni-consciousness existed for a millisecond, a millennium or an eternity. But it jabbed with its thoughts at the weathered fabric between realities and poked an infinitesimal hole. And the entirety of a neighbouring universe endless space and matter - flooded through that pinhole in a spectacular cosmic eruption. The omni-consciousness found that matter, gave it form, and it revelled in its multitudinous shapes. It discovered that matter - moulded by the flame of time and the winds of evolution - could eventually give rise to its own self-aware components, part of the omni-consciousness, yet separate from it. It delighted in each of the quadrillions of consciousnesses that flickered into and out of existence. It no longer knew loneliness. Time, space and matter continued to expand - prodded into acceleration by the omni-consciousness - hoping in vain to fill every crevice of infinity. This has happened in every bubble of the transreality-froth we've explored.

\section{Can you describe a clean source of} unlimited energy that we can utilize?

$<$ File attached $>$ You are already on the verge of discovering this for yourselves. We were very much like you at one time, distracted by the mundane. You're capable of accomplishing more than you can imagine.

What is the nature of reality and what part does quantum physics play in it? You have a fundamental misunderstanding of quantum phenomena: particles briefly effervescing into existence, waves of probability collapsing into a particular reality, the entanglement of photons without regard to distance. The reason you can't reconcile these quantum events with the physical laws of your universe is because they are sparks of a superjacent reality in the froth, where the veil of your universe is worn thin. Eventually you too will be able to peer past that veil, if only for a limited amount of time, as we do now during this exchange.

How can we maintain our cultural and military superiority over those who would seek to undermine our way of life?

You've wasted much time in our prior two exchanges with questions like these. You're better than this. If this is to be our final communication before the fissure closes, you should endeavour to make it more productive.

\section{What question should we have asked} you that we didn't?

We wish you would have asked us about something important. About love. About compassion.

We weren't always sure we'd be able to overcome our own primitive aggressive impulses. Our species evolved from an apelike mammal on a blue water-world circling a yellow sun, and, like you, we engaged in countless meaningless wars during our infancy. This is a familiar pattern, part of the growing pains all sentient species experience. So we take these final few seconds to urge you: imagine the inconceivable, strive for the impossible. The cosmic path is clear; you're on your way. And it's going to be an amazing journey, we promise.

Mercurio Rivera (www.mercuriorivera. com) is a New York attorney and sciencefiction writer whose stories have appeared in Interzone, Unplugged: The Web's Best Sci-Fi and Fantasy - 2008 Download (Wyrm Publishing) and elsewhere. Join the discussion of Futures in Nature at http://tinyurl.com/kkh3kt 